\title{
Analisa Perbandingan Torsi dan RPM Turbin Tipe Darrieus Terhadap Efisiensi Turbin
}

\author{
Aris Febrianto, Agoes Santoso \\ Jurusan Sistem Perkapalan, Fakultas Teknologi Kelautan, Institut Teknologi Sepuluh Nopember (ITS) \\ Jl. Arief Rahman Hakim, Surabaya 60111 Indonesia \\ e-mail: arisfebriato86@gmail.com
}

\begin{abstract}
Abstrak-Telah dilakukan studi eksperimental untuk mengetahui pengaruh Mekanisme Active Pitch pada Turbin Hidrokinetik Tipe Darrieus terhadap efisiensi turbin. Eksperimen dilakukan di Umbulan, Pasuruan. Variasi kecepatan yang digunakan untuk eksperimen adalah 0.674 $\mathrm{m} / \mathrm{s}, 0.806 \mathrm{~m} / \mathrm{s}, 0.944 \mathrm{~m} / \mathrm{s}$ dengan menggunakan 3 variasi jumlah foil, 3,6 dan 9 foil . Hasil yang diperoleh adalah pengukuran nilai rerata Torsi maksimum mekanisme 3 foil pada kecepatan $0.944 \mathrm{~m} / \mathrm{s}$ sudut azimuth $30^{\circ}$ sebesar $5.36 \mathrm{Nm}$, sedangkan rerata RPM maksimum pada kecepatan $0.944 \mathrm{~m} / \mathrm{s}$ sebesar 21.1 Rpm. Sedangkan 6 foil hasil pengukuran nilai rerata Torsi maksimum pada kecepatan $0.944 \mathrm{~m} / \mathrm{s}$ sudut azimuth $30^{\circ}$ sebesar $5.4 \mathrm{Nm}$, sedangkan rerata RPM maksimum pada kecepatan $0.944 \mathrm{~m} / \mathrm{s}$ sebesar $12.5 \mathrm{Rpm}$. Sedangkan 9 foil menghasilkan pengukuran nilai rerata Torsi maksimum pada kecepatan $0.944 \mathrm{~m} / \mathrm{s}$ sudut azimuth $30^{\circ}$ sebesar $5.45 \mathrm{Nm}$, sedangkan rerata RPM maksimum pada kecepatan $0.944 \mathrm{~m} / \mathrm{s}$ sebesar $10.9 \mathrm{Rpm}$. Data hasil pengukuran tersebut dapat disimpulkan bahwa variasi 3 foil memiliki efisiensi turbin terbaik dengan nilai $91.6 \%$ pada kecepatan arus $0.994 \mathrm{~m} / \mathrm{s}$.
\end{abstract}

Kata Kunci-Turbin Hidrokinetik, Darrieus, Mekanisme Active Pitch, Efisiensi Turbin.

\section{PEndahuluan}

$\mathrm{R}$ endahnya ketahanan negara di bidang energi merupakan salah satu penghambat pertumbuhan ekonomi nasional Permintaan sumber energi nasional yang paling tinggi diduduki oleh batu bara sebesar $40 \%$ dan minyak bumi sebesar $23 \%$, lalu diikuti oleh gas sebesar $22 \%$, panas bumi sebesar $3 \%$ serta sumber energi terbarukan lainnya sebesar $12 \%$. Alasan ini menjadikan peluang untuk pengembangan energi alternatif terbarukan yang ramah lingkungan. Indonesia merupakan negara maritim yang sebagian besar luas wilayahnya didominasi oleh laut yang luas. Oleh karena itu, diperlukan peningkatan penggunaan sumber energi arus laut dalam memenuhi kebutuhan listrik di Indonesia[2]. Arus laut memiliki energi kinetik yang besar dengan kecepatan arus laut di beberapa perairan Indonesia seperti Bali dan Nusa Tenggara mencapai 0,5 $3,4 \mathrm{~m} / \mathrm{s}$ [1]. Maka dari itu, pemanfaatan Turbin Hidrokinetik sebagai pengkonversi energi dioptimalkan untuk dapat mengekstrak energi kinetik arus laut menjadi energi listrik. Jenis turbin hidrokinetik mengadopsi desain dan teori dari wind turbine yaitu jenis horizontal aksis dan jenis vertikal aksis[13].Turbin vertikal aksis sangat cocok jika digunakan untuk perairan Indonesia karena kecepatan aliran yang dimiliki pada kriteria sedang (low Tip Speed Ratio). Turbin Hidrokinetik yang sering dikembangkan salah satunya adalah tipe Darrieus. Turbin Darrieus memiliki efisiensi cukup baik jika dibandingkan dengan tipe Savonnius walau dalam aplikasinya masih memiliki torque ripple besar dan lift and drag yang bervariasi[7]. Beberapa riset telah dilakukan untuk memanfaatkan mekanisme fixed pitch dan variable pitch dalam mengoptimalkan nilai gaya lift sebagai gaya penggerak turbin untuk setiap pergerakan foil di sepanjang sudut azimuth. Beberapa hasil simulasi terhadap turbin sumbu vertikal aksis telah menyimpulkan bahwa mekanisme variable pitch sebagai perubahan sudut serang mampu mempengaruhi nilai torsi yang dihasilkan[3]. Pada kondisi yang sama, Hantoro telah melakukan investigasi eksperimen pada passive pitch turbin arus laut vertical aksis menggunakan 3-straight bladed NACA 0018. Hantoro juga menjelaskan Lift and Drag Force yang sangat berpengaruh terhadap performansi dan efisiensi turbin Darrieus telah dapat ditingkatkan dengan mekanisme Passive Pitch[4]. Di samping itu, studi eksperimental flapping wing sebagai mekanisme passive pitch pada turbin 3 straight-blade tipe Darrieus untuk variasi sudut pitch $10^{\circ}$ dan $20^{\circ}$ [8]. Namun hasil eksperimen menunjukkan kekurangan dalam perolehan gaya angkat foil terbaik di setiap travelling rotasi, yaitu pada azimuth $0^{\circ}$ dan $90^{\circ}$ menghasilkan nilai gaya drag yang cukup besar akibat sudut serang foil yang tidak optimal. Kemudian eksperimen mengenai kombinasi cascade foil antara fixed pitch dan passive pitch telah dilakukan dan diketahui pengaruh dari variasi kecepatan aliran dan jumlah foil pada turbin Darrieus terhadap nilai solidity, torsi, dan rpm[9]. Dari beberapa pernyataan tersebut, kekurangan mekanisme fixed dan passive pitch yang akan dijadikan topik eksperimen dari perkembangan turbin hidrokinetik tipe Darrieus menggunakan airfoil straight-bladed NACA 0018 untuk memaksimalkan gaya lift dengan mencari sudut serang terbaik di setiap $15^{\circ}$ pergerakan foil di sepanjang azimuth rotasi. Penelitian ini difokuskan pada analisis mekanisme active pitch Turbin Hidrokinetik tipe Darrieus menggunakan airfoil NACA 0018 dengan mengacu pada grafik Lift/Drag Coefficient terhadap nilai Angle of attack pada NACA 0018 dengan Reynold Number 300.000[5]. Analisis dilakukan dengan studi eksperimental untuk menganalisis aerodinamika yang terjadi akibat mekanisme active pitch berupa actuator disc yang terpasang pada foil turbin Darrieus dan membandingkan data eksperimen tersebut dengan mekanisme fixed pitch dan passive pitch.

\section{DASAR TEORI}

\section{A. Pemanfaatan Energi Arus Laut}

Teknologi turbin hidrokinetik sudah sangat populer digunakan untuk menghasilkan listrik yang biasa disebut Pembangkit Listrik Tenaga Air (PLTA). Sistem pembangkit ini mempunyai cara kerja yang berbeda - beda tergantung dari kondisi dan tempat yang akan dimanfaatkan. Secara umum Turbin hidrokinetik dibagi menjadi tiga jenis yakni Cross-Flow turbine, Horizontal Axis Turbine (HAT) dan Vertical Axis Turbine (VAT). 


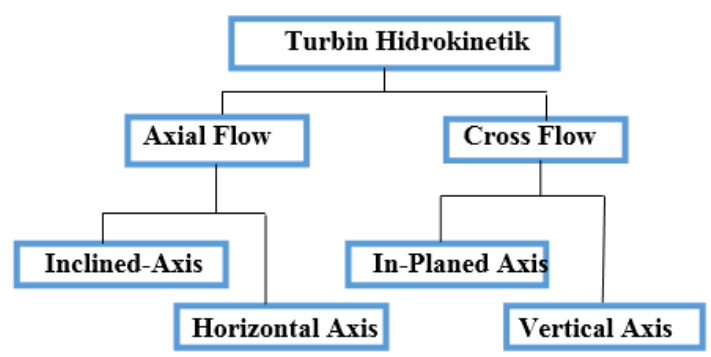

Gambar 1. Klasifikasi Turbin Hidrokinetik [6]

Untuk mendesain turbin arus laut, perlu diperhatikan tentang bentuk dan jumlah blade yang digunakan. Bentuk dari blade itu juga tergantung dari karakteristik aliran di suatu tempat, ketika sudah diketahui karakteristik aliran kemudian dapat ditentukan bentuk sudu/blade mana yang akan digunakan. Masing-masing tipe turbin pada Gambar.1 menjelaskan model Horizontal Axis dan Vertical Axis. Jenis Savonius memilki daya putaran yang sangat rendah namun gaya drag berfungsi menangkap aliran arus fluida. Kekurangan turbin Savonius yang memanfaatkan gaya drag yaitu tidak dapat berputar kencang bila kurang angin dan tidak baik diterapkan pada area yang memiliki kecepatan rendah. Sedangkan untuk jenis turbin Darrieus memiliki efisiensi dan performansi yang lebih tinggi pada kecepatan arus rendah, tetapi memiliki self-start buruk sehingga dibutuhkan mekanisme variable pitch untuk mengoptimalkan gaya lift yang bekerja.

\section{B. Prinsip Kerja Turbin Darrieus}

Turbin Darrieus merupakan turbin yang menggunakan foil untuk menghasilkan gaya angkat.

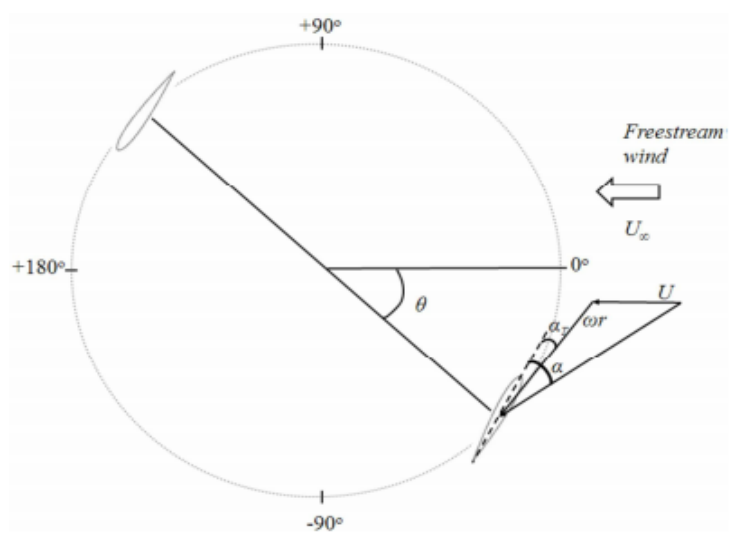

Gambar 2. Prinsip Kerja Turbin Darrieus[11]

Turbin jenis Darrieus dapat mengubah torsi ketika foil bergerak relatif lebih cepat terhadap aliran yang datang dan beroperasi pada low Tip Speed Ratio ${ }^{[11]}$. Sehingga memiliki efisiensi yang lebih besar daripada turbin yang memanfaatkan drag. Gambar 2 menunjukan garis vektor percepatan dari bentuk airfoil pada sudut azimuth yang berbeda. Foil pada turbin Darrieus berotasi dan terjadi perubahan aliran relatif. Pada sudut serang yang kecil, gaya lift kecil yang dihasilkan foil akan memiliki gaya tangensial yang fluktuatif akibat sudut serang bervariasi.

\section{Reynold Number}

Reynold Number adalah rasio antara gaya inersia (vs $\rho$ ) terhadap gaya viskos $(\mu / \mathrm{L})$ yang mengkuantifikasikan hubungan kedua gaya tersebut dengan suatu kondisi aliran tertentu. Bilangan ini digunakan untuk mengidentikasikan jenis aliran yang berbeda, misalnya laminar dan turbulen.

$$
R e=\frac{\rho w D}{\mu}
$$

\section{Mekanisme Pitch Turbin Darrieus}

Untuk meningkatkan efisiensi dan kinerja turbin salah satunya dengan pemanfaatan mekanisme Variable Pitch berupa pergerakan foil dan perubahan sudut serang untuk meningkatkan performa turbin. Tipe pitch dikelompokan menjadi dua, yaitu fixed pitch dan variable pitch. Fixed pitch merupakan suatu cara yang digunakan pada sebuah turbin di mana foil dikondisikan tidak dapat bergerak sepanjang azimuth. Fixed pitch apabila diterapkan pada sebuah turbin memiliki beberapa sifat, yaitu dapat diterapkan dengan mudah dan perawatan yang tidak rumit. Namun pada jenis ini, turbin akan memiliki sifat self start sangat berat. Hal ini dikarenakan bahwa pada fase awal terdapat turbin yang memiliki permukaan yang luas yang dapat menghilangkan gaya angkat yang disebut dengan fenomena stall yang dapat menurunkan efisiensi dan menimbulkan keadaan fatigue. Pada variable pitch, terdapat dua macam tipe yaitu pasif dan aktif. Pada tipe active pitch, foil telah dikontrol untuk dapat bergerak dengan sudut serang tertentu. Sedangkan pada passive pitch, yaitu dengan mengkondisikan airfoil yang dibatasi pergerakanya dalam membentuk sudut serang tertentu.

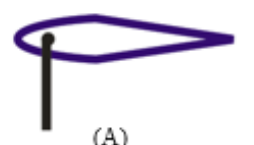

(A)

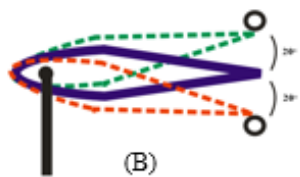

Gambar 3. Mekanisme Pergerakan foil : A) mekanisme fixed pitch B) mekanisme variable pitch [4]

\section{E. Performansi dan Efisiensi Turbin Darrieus}

Dari persamaan fisika dasar maka dapat dicari daya yang dihasilkan turbin adalah sebagai berikut :

$$
\begin{aligned}
& W=F . S \\
& P=\frac{W}{t}
\end{aligned}
$$

Dengan subtitusi persamaan 2.5 dan 2.6 maka dihasilkan :

$$
\begin{aligned}
& P=F \cdot \frac{s}{t} \\
& P=F \cdot v \\
& P=(F . r)\left(\frac{v}{r}\right)
\end{aligned}
$$

Pturbin $=\tau . \omega$

Kecepatan sudut $(\omega)$ dapat dikonversi dari nilai RPM yakni:

$$
\omega=\frac{2 \pi R P M}{60}
$$

Berdasarkan hasil penurunan rumus di atas maka diperlukan nilai torsi terukur dan nilai RPM terukur. Setelah diperoleh nilai daya mekanik dan daya air dari turbin maka didapatkan nilai efisiensi dari turbin yang merupakan hasil pembagian antara daya mekanik turbin dan daya air. Sehingga koefisien daya (Cp) dapat dijabarkan sebagai berikut.

$$
C p=\frac{\text { Pturbin }}{\text { Pair }}
$$

Dan persentase efisiensi turbin dapat diketahui dengan persamaan

$$
\eta=C p * 100
$$


Nilai Tip Speed Ratio (TSR) adalah perbandingan antara kecepatan tangensial di ujung rotor terhadap kecepatan fluida yang mengaliri turbin tersebut. Maka TSR dapat dijabarkan dengan persamaan berikut:

$$
T S R=\frac{\omega r}{v_{\text {air }}}
$$

Setelah data perhitungan didapat maka efisiensi dan performansi turbin dapat diketahui trennya setelah dibuat grafik antara $\mathrm{Cp}$ dan TSR.

\section{METODE EKSPERIMEN}

Referensi yang digunakan mencakup materi turbin hidrokinetik vertical axis tipe Darrieus, memahami tentang karakteristik airfoil NACA 0018, pemahaman tentang aliran benda terendam, aliran kanal terbuka, pemahaman pengaruh turbin terhadap mekanisme Variable Pitch, pemahaman mekanisme fixed dan variable pitch terhadap performansi turbin, pemahaman tentang flow separation, aspek rasio pada perancangan turbin, pengambilan data dimulai dari kanal yang akan digunakan tempat eksperimen ditunjukan pada Gambar.4. Kecepatan aliran sungai, dan lebar sungai serta kedalaman dan debit sungai dapat ditunjukan oleh Tabel.1 dan terukur 3 variasi kecepatan yang berbeda yakni $0.674 \mathrm{~m} / \mathrm{s}, 0.806 \mathrm{~m} / \mathrm{s}$, dan $0.994 \mathrm{~m} / \mathrm{s}$ serta telah diketahui nilai viskositas air $(\boldsymbol{\mu})$ pada suhu $23^{\circ} \mathrm{C}$ adalah $1.1375 \times 10-3$ Pa.s.

\begin{tabular}{cc} 
TABEL 1. UKURAN DAN KARATERISTIK TEMPAT PENGUJIAN \\
\hline \hline Jenis aliran & Aliran Kanal Terbuka \\
\hline Lebar Kanal & 1 meter \\
Kedalaman & 1,8 meter \\
Kecepatan Aliran & 0.67 s.d. $0.994 \mathrm{~m} / \mathrm{s}$ \\
Temperatur air & $23^{\circ} \mathrm{C}$ \\
\hline \hline
\end{tabular}

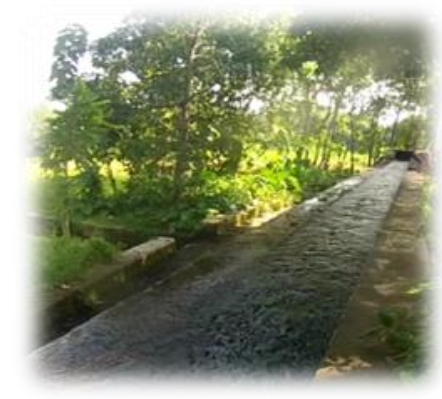

Gambar 4. Obyek pengujian berupa aliran kanal terbuka

Langkah selanjutnya adalah penentuan variabel bebas yaitu kombinasi antara kecepatan aliran dan mekanisme pitch pada turbin ditunjukkan Gambar.4

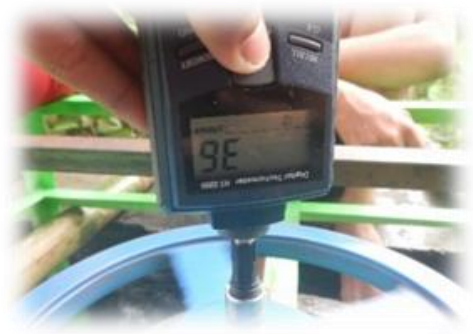

Gambar 5. Pengambilan Data RPM

Pada pengambilan data dibutuhkan data RPM sebanyak 10 kali per titik variasi kecepatan dan Torsi pada setiap perubahan $30^{\circ}$ sudut azimuth sebanyak 10 kali per titik variasi kecepatan ditunjukan pada Gambar.5 dan Gambar.6. Kemudian diambil rerata Torsi dan RPM sehingga didapatkan data hasil eksperimen dan hasil tersebut dianalisis. Setalah dianalisis, data tersebut diambil kesimpulan bagaimana karakteristik dari mekanisme active pitch bila dibandingkan dengan fixed maupun passive pitch. Penyusunan laporan adalah tahap terakhir setalah analisa data dan kesimpulan diperoleh.

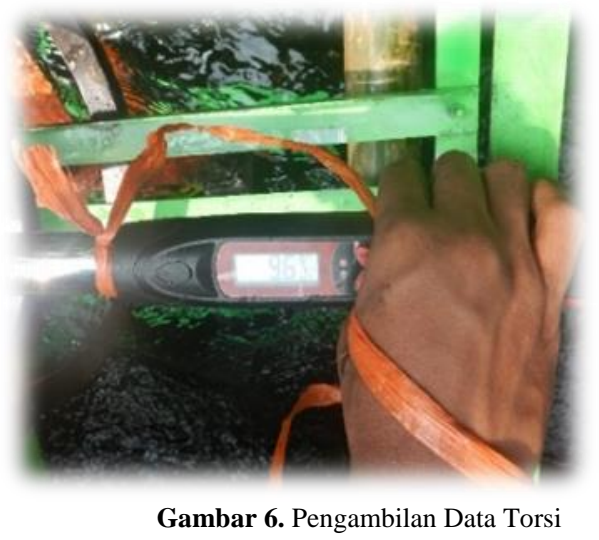

\section{DISKUSI DAN PEMBAHASAN}

\section{A. Lokasi eksperimen}

Lokasi Eksperimen turbin arus sungai ini bertempat di daerah Umbulan - Pasuruan, Jawa Timur. Di tempat ini terdapat kanal terbuka yang memiliki karakteristik yang sesuai dan dibutuhkan untuk eksperimen dan penelitian ini. Pada kanal tersebut memiliki perbedaan kecepatan aliran signifikan pada setiap titik tertentu sungai tersebut.

Kecepatan aliran tersebut akan digunakan untuk variasi dalam uji coba turbin dengan 3 variasi mekanisme pitch di sepanjang kanal tersebut. Berikut adalah profil kecepatan arus sungai dalam bentuk tabel

TABEL 2. DATA LOKASI EKSPERIMEN

\begin{tabular}{|c|c|c|c|c|c|}
\hline No. & Lokasi & $\begin{array}{c}\text { Lebar } \\
\text { permukaan } \\
\text { air }(\mathbf{m})\end{array}$ & $\begin{array}{c}\text { Kedalaman } \\
\text { air }(\mathbf{m})\end{array}$ & $\begin{array}{c}\text { Jarak pondasi } \\
\text { sungai ke } \\
\text { permukaan air }(\mathbf{m})\end{array}$ & $\begin{array}{c}\text { Kecepatan aliran } \\
\text { permukaan air } \\
(\mathbf{m} / \mathbf{s})\end{array}$ \\
\hline 1. & $\begin{array}{c}\text { Umbulan } \\
\text { A }\end{array}$ & 1,02 & 1,6 & 0,09 & 1.017 \\
\hline 2. & $\begin{array}{c}\text { Umbulan } \\
\text { B }\end{array}$ & 1,03 & 1,5 & 0,11 & 0,806 \\
\hline 3. & $\begin{array}{c}\text { Umbulan } \\
\text { C }\end{array}$ & 1,04 & 1,58 & 0,15 & 0,67 \\
\hline
\end{tabular}

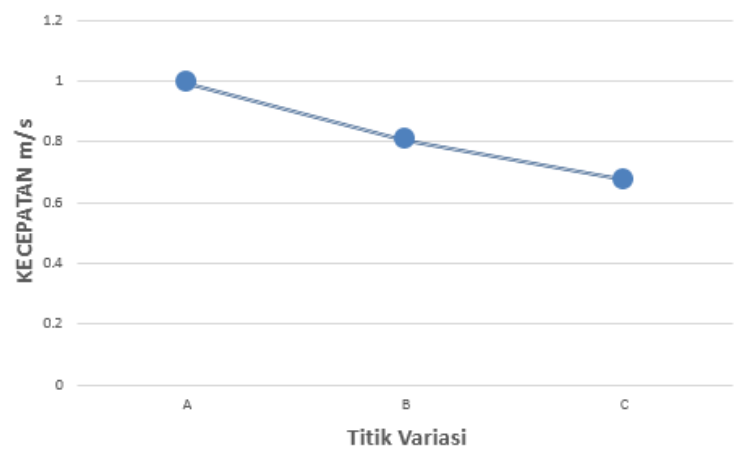

Gambar 7. Grafik profil kecepatan arus pada 3 titik lokasi umbulan

\section{B. Tahap eksperimen}

Pada tahap eksperimen ini dilakukan pengambilan data pada 3 titik variasi kecepatan aliran arus sungai berupa RPM dan Torsi. Pada eksperimen ini, pengambilan data diawali dengan pengukuran kecepatan aliran arus sungai menggunakan Current Meter dengan propeller sebagai sensor mekanik dan $\mathrm{m} / \mathrm{s}$ sebagai satuan pembacaan kecepatan aliran dari debit kanal terbuka. 


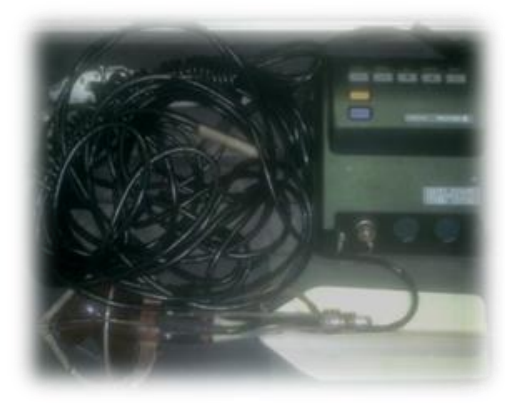

Gambar.8. Alat ukur current meter

Pengukuran yang dilakukan di sepanjang kanal terbuka daerah Umbulan dengan 5 kali pengambilan data per titik lokasi :

TABEL 3. RATA RATA KECEPATAN ARUS AIR (M/S)

\begin{tabular}{cccc}
\hline \hline No. & A & B & C \\
\hline 1 & 1.116 & 0.799 & 0.675 \\
2 & 0.983 & 0.819 & 0.615 \\
3 & 0.972 & 0.799 & 0.690 \\
4 & 0.979 & 0.798 & 0.683 \\
5 & 0.993 & 0.825 & 0.710 \\
Rata-rata & 0.994 & 0.806 & 0.6746 \\
\hline \hline
\end{tabular}

Setelah dilakukan pengukuran kecepatan arus air maka dilakukan eksperimen untuk menghitung torsi dan RPM pada turbin dengan variasi 3,6 dan 9 blade.

Berikut merupakan hasil pengukuran torsi turbin dengan perbandingan jumlah foil yang berbeda.

\begin{tabular}{cccc}
\multicolumn{4}{c}{ TABEL 4. RATA RATA NILAI TORSI (N/M) } \\
\hline \hline Sudut Azimuth & 3 foil & 6 foil & 9 foil \\
\hline 0 & 5.23 & 52 & 5.56 \\
30 & 5.43 & 5.73 & 5.53 \\
60 & 5.3 & 5.6 & 5.36 \\
90 & 5.53 & 5.4 & 5.6 \\
120 & 5.33 & 5.1 & 5.36 \\
150 & 5.43 & 5.1 & 5.3 \\
180 & 5.4 & 5.46 & 5.4 \\
210 & 5.2 & 5.3 & 5.43 \\
240 & 5.7 & 5.36 & 5.6 \\
270 & 5.33 & 5.3 & 5.8 \\
300 & 5.33 & 5.66 & 5.33 \\
330 & 5.16 & 5.63 & 5.23 \\
Rata-rata & 5.36 & 5.4 & 5.45 \\
\hline \hline
\end{tabular}

Dari hasil tabel diatas dapat diketahui bahwa torsi tertinggi tercatat pada percobaan 9 foil dan semakin rendah pada 6 foil. Sedangkan 3 foil mempunyai nilai torsi paling rendah.

TABEL 5. RATA RATA NILAI RPM

\begin{tabular}{cccc}
\hline \hline No. & 3 foil & 6 foil & 9 foil \\
\hline 1 & 17 & 12 & 11 \\
2 & 19 & 14 & 12 \\
3 & 22 & 13 & 10 \\
4 & 23 & 12 & 12 \\
5 & 20 & 13 & 11 \\
6 & 21 & 14 & 10 \\
7 & 22 & 11 & 12 \\
8 & 22 & 12 & 10 \\
9 & 24 & 11 & 11 \\
10 & 21 & 13 & 10 \\
rata-rata & 21.1 & 12.5 & 10.9 \\
\hline \hline
\end{tabular}

\section{Perhitungan daya mekanik turbin}

Performansi dari turbin merupakan daya mekanik yang dihasilkan dari sebuah turbin. Untuk mendapatkan nilai performansi maka data yang dibutuhkan adalah putarab dari turbin atau RPM $(\omega)$ dan torsi (T). Persamaan untuk menghitung performansi turbin adalah sebagai berikut :

$$
\begin{aligned}
& W_{s}=T . \omega \\
& \text { T 3foil }=5.36 \\
& \text { T } 6 \text { foil }=5.4 \\
& \text { T 9foil }=5.45 \\
& \omega \text { 3foil }=21.1 \\
& \omega \text { 6foil }=12.5 \\
& \omega \text { 9foil }=10.9 \\
& \\
& \mathrm{~W}_{\mathrm{s}} \text { 3foil }=5.36 \times 21.1=\mathbf{1 1 3 . 0 9 6} \mathbf{~ J} / \mathbf{s} \\
& \mathrm{W}_{\mathrm{s}} \text { 6foil }=5.4 \times 12.5=\mathbf{6 7 . 5} \mathbf{~} / \mathbf{s} \\
& \mathrm{W}_{\mathrm{s}} \text { 9foil }=5.45 \times 10.9=\mathbf{5 9 . 4 0 5} \mathbf{~ J / s}
\end{aligned}
$$

\section{Perhitungan efisiensi turbin}

Untuk menentukan efisisensi turbin tersebut dapat dicari dengan menggunakan model streamtube analysis yaitu dengan cara membandingkan daya keluaran pada turbin dengan kinetic energi flux. Berikut adalah persamaan untuk mecari efisiensi dari turbin tersebut :

$$
\eta=\frac{P}{K E F}
$$

Dengan :

$\mathrm{P} \quad=$ daya keluaran turbin

$\mathrm{KEF} \quad=$ Kinetic Energi Flux

$$
K E F=\frac{1}{2} \rho v^{3} 2 \pi r l
$$

Dengan :

$$
\begin{aligned}
& \rho \quad=\text { massa jenis fluida } \\
& \mathrm{v}=\text { kecepatan fluida sebelum turbin } \\
& \mathrm{r} \quad=\text { jari-jari turbin } \\
& 1=\text { panjang blade } \\
& \text { P 3foil }=113.096 \mathrm{~J} / \mathrm{s} \\
& \mathrm{P} \text { 6foil }=67.5 \mathrm{~J} / \mathrm{s} \\
& P \text { 9foil }=59.405 \mathrm{~J} / \mathrm{s} \\
& \rho=1000 \mathrm{~kg} / \mathrm{m}^{3} \\
& \mathrm{v}=0.994 \mathrm{~m} / \mathrm{s} \\
& \mathrm{r}=0.2 \mathrm{~m} \\
& 1=0,4 \mathrm{~m} \\
& \begin{aligned}
K E F & =1 / 2 \times 1000 \times(0.994)^{3} \times 3.14 \times 0.2 \times 0.4 \\
& =\mathbf{1 2 3 . 3 5} \mathbf{~ J / s}
\end{aligned} \\
& \eta_{6} \text { foil }=113.096 / 123.35 \times 100 \%=\mathbf{9 1 . 6 \%} \\
& \eta_{6 \text { foil }}=67.5 / 123.35 \times 100 \% \quad=\mathbf{5 4 . 7 \%} \\
& \eta_{\text {}} 9 \text { foil }=59.405 / 123.35 \times 100 \%=\mathbf{4 8 . 1 5 \%}
\end{aligned}
$$

Dari hasil diatas telah didapatkan angka efisiensi dari turbin dengan 3 foil mendapatkan efisiensi tertinggi mencapai 91.6\%, sedangkan yang menggunakan 6 foil mendapat angka $54.7 \%$. Nilai efisiensi paling rendah adalah $48.15 \%$ ketika memakai 9 foil.

\section{PENUTUP}

\section{A. Kesimpulan}

Berdasarkan pengukuran, analisa, dan pembahasan yang telah dilakukan maka kesimpulan yang dapat ditarik dari penelitian ini adalah:

1. Hasil dari variasi 3 foil pada kecepatan $0.944 \mathrm{~m} / \mathrm{s}$ sudut azimuth $30^{\circ}$ mendapatkan torsi rata-rata sebesar 5.36 $\mathrm{Nm}$, sedangkan rerata RPM maksimum pada kecepatan $0.944 \mathrm{~m} / \mathrm{s}$ sebesar $21.1 \mathrm{Rpm}$. 
2. Hasil dari variasi 6 foil pada kecepatan $0.944 \mathrm{~m} / \mathrm{s}$ sudut azimuth $30^{\circ}$ mendapatkan torsi rata-rata sebesar $5.4 \mathrm{Nm}$, sedangkan rerata RPM maksimum pada kecepatan 0.944 $\mathrm{m} / \mathrm{s}$ sebesar $12.5 \mathrm{Rpm}$.

3. Hasil dari variasi 3 foil pada kecepatan $0.944 \mathrm{~m} / \mathrm{s}$ sudut azimuth $30^{\circ}$ mendapatkan torsi rata-rata sebesar 5.45 $\mathrm{Nm}$, sedangkan rerata RPM maksimum pada kecepatan $0.944 \mathrm{~m} / \mathrm{s}$ sebesar $10.9 \mathrm{Rpm}$.

4. Variasi 3 foil memiliki nilai efisiensi turbin terbaik dengan nilai $91.6 \%$ pada kecepatan arus $0.994 \mathrm{~m} / \mathrm{s}$. Sedangkan 6 foil hanya mencapai $54.7 \%$. Dan yang paling rendah 9 foil dengan efisiensi $48.15 \%$

B. Saran

Beberapa saran yang perlu dipertimbangkan setelah dilakukan eksperimen mengenai variasi jumlah hydrofoil dan perpaduan antara variabel passive-pitch dan fixed-pitch adalah :

1. Mencari tempat pengambilan data dengan lokasi yang mempunyai range kecepatan aliran yang bervariasi rendah - sedang $(0.4$ s.d. $1.4 \mathrm{~m} / \mathrm{s})$.

2. Dalam hal ini mekanisme active pitch pada turbin Darrieus masih perlu dikembangkan lagi agar performansinya dapat melebihi mekanisme passive pitch.

\section{DAFTAR PUSTAKA}

[1] Lubis, Yuningsih, "Preliminary Research of Using Ocean Currents and Wind Energy to Support Lighthouse in small island, Indonesia," Conference and Exhibition Indonesia Renewable Energy \& Energy Conservation.2013

[2] Ray R.D., G.D.Egbert."A Brief Overview of Tides in the Indonesian Seas," Oceanography, 18, 74-79.2005.

[3] Shah Khalid, Syed. "Difference between Fixed and Variable Pitch
Vertical Axis Tidal Turbine-Using CFD Analysis in CFX". Harbin Engineering University, China. Maxwell Scientific Organization. Research Journal Applied Science, Engineering and Technology 5(1); 319-325, 2013.

[4] Hantoro, Ridho."An Experimental Investigation of Passive Variable Pitch Vertical-Axis Ocean Current Turbine", Institut Teknologi Bandung, Bandung.2011.

[5] W.A.Timmer. 2008. "Two-Dimensional Low Reynold Number Wind Tunnel Results For Airfoil NACA 0018,". Wind Engineering Volume 32. No.6 (2008) Pp.525-537.

[6] Khan, M.J,"Hydrokinetic energi conversion systems and assessment of horizontal and vertikal axis turbines for river and tidal applications: A technology status review" Power system technologies, Canada, 2009

[7] Guney M.S., Kaygusz K.,"Hydrokinetic Energy Conversion System: A Technology Status Review", Renewable and Sustainable Energy Reviews 2010. 2996-3004

[8] Garynda Adetama Gunawan, Mecha. 2014. "Studi Eksperimental Mekanisme Passive-Pitch Dengan Flapping Wing Pada Turbin Vertikal Aksis Tipe Darrieus". Sukolilo, Surabaya.

[9] Widya Mandala, Seno. 2015. "Rancang Bangun Turbin Arus Lau Vertikal Aksis Straight Bladed Cascade untuk mengetahui pengaruh variasi jumlah Foil terhadap Efisiensi Turbin," Sukolilo, Surabaya.

[10] Jing, Fengmei. 2014. "Experimental research on tidal current vertica axis turbine with variable-pitch blades". Deep Water Engineering Research Centre, Ocean Engineering 88(2014) 228-241.

[11] Malge, Pawar. 2015."Analysis of Lift and Drag Forces at Different Azimuth Angle of Innovative Vertical Axis Wind Turbine," InternationalJournal of Energy Engineering 4(5-8).

[12] Erich Hau,"Wind Turbines: Fundamentalss, Technologies, Applications, and Economics," 2 ${ }^{\text {nd }}$ Edition.Springer

[13] Paraschivoiu, I..2002. "Wind Turbine Design with Emphasis on Darrieus Concepts,”. Polytechnic International Press 